\title{
Management of Rotator Cuff Injuries in the Elite Athlete
}

\author{
Leigh J. Weiss ${ }^{1} \cdot$ Dean Wang $^{2} \cdot$ Michael Hendel $^{2} \cdot$ Philip Buzzerio $^{1} \cdot$ Scott A. Rodeo ${ }^{3}$ \\ Published online: 13 January 2018 \\ (C) Springer Science+Business Media, LLC, part of Springer Nature 2018
}

\begin{abstract}
Purpose of Review Rotator cuff injuries are a common cause of pain and dysfunction for the elite athlete and can result in time loss from participation. This review highlights the current management of these injuries.

Recent Findings Conservative management of rotator cuff injuries continues to be the "gold standard" in the elite athlete. This includes a comprehensive rehabilitation program, anti-inflammatories, and corticosteroid injections. Newer treatment techniques such as intramuscular dry needling and the use of biologics such as platelet-rich plasma and stem cells demonstrate early promising results; however, these modalities require further investigation to determine their effectiveness.

Summary Rotator cuff injuries can range from contusions and tendinopathy to full-thickness tears. A comprehensive evaluation is needed to determine the extent of injury and appropriate plan of care. Management strategies can range from rehabilitation to operative intervention and are guided by the size of the tear, time of season, sport, performance limitations, and presence of concomitant pathology.
\end{abstract}

Keywords Rotator cuff $\cdot$ Elite athlete $\cdot$ Rehabilitation $\cdot$ Shoulder

\section{Introduction}

Injuries to the rotator cuff are a common source of pain and dysfunction in athletes across all sports and levels of competition. These injuries can also have a significant impact on playing career and can limit the athlete's ability to participate in competitive sports [1]. Due to the demands of sport, rotator cuff injuries have been shown to occur more frequently in both overhead and contact athletes [2,3]. A study by a single professional football team reported that rotator cuff contusions accounted for $47 \%$ of all shoulder injuries [4]. In collegiate football, rotator cuff injuries have been shown to be the third most common injury of the shoulder [5]. In a review by Gibbs et al. [6•], draft-eligible football players who sustained an injury to the rotator cuff were significantly less likely to be

This article is part of the Topical Collection on Rotator Cuff Repair

Scott A. Rodeo

rodeos@hss.edu

New York Football Giants, East Rutherford, NJ, USA

2 Hospital for Special Surgery, New York, NY, USA

3 Sports Medicine and Shoulder Service, Hospital for Special Surgery, 535 East 70th Street, New York, NY 10021, USA drafted than those without a previous injury. Drafted players who reported previous rotator cuff injury started significantly fewer games and played significantly fewer years than their matched controls. A previous study of Major League Baseball pitchers demonstrated that pitchers with rotator cuff injuries that eventually required surgery demonstrated gradual decline in their performance leading up to surgical intervention [1].

In the elite athlete, injuries to the rotator cuff can result from an acute episode of trauma such as a direct blow, falling on an outstretched arm or from chronic overuse and repetitive microtrauma. Injuries can present along a spectrum of severity, ranging from rotator cuff contusions and tendinopathies to rotator cuff tears. Rotator cuff tears can be classified as either partial-thickness of full-thickness disruptions. Rotator cuff injuries in the overhead throwing athlete are believed to occur from repetitive tensile overload with eccentric contraction during the deceleration phase of the throwing motion [7-9]. Tears to the articular side of the rotator cuff are more common than bursal sided tears and are often the type of tear seen in overhead athletes $[10,11]$. Many of these tears are located posterosuperiorly at the junction of the supraspinatus and infraspintatus tendonous attachments to the humerus [12, 13]. From our experience, injuries to the rotator cuff in the elite athlete can often result in missed time in training, practice, and competition. 
Management of injuries to the rotator cuff is guided by the type of injury and severity. Injuries to the rotator cuff can be treated either conservatively or surgically, and this decision is often based on the patient's age, size of tear, location of tear, performance limitations, and presence of concomitant injuries. Furthermore, in the elite athlete, there are many other factors for the treating clinician to consider. These include sport, level of contact, positional demands, time of year, and both post-season and financial implications.

There are many studies that examine the management and rehabilitation of post-operative rotator cuff repairs; however, little information exists on the in-season management of these injuries in the elite athlete. The aim of this review is to examine the current in-season management of rotator cuff injuries in elite athletes.

\section{Relevant Anatomy}

The glenohumeral joint is the most mobile joint in the human body. As a result, it requires intricate coordination of the surrounding musculature to maintain stability during functional activities. The rotator cuff is key to maintaining glenohumeral joint stability by maintaining centering of the humeral head on the glenoid fossa during active shoulder motion. The rotator cuff assists with elevating the arm while creating a force couple by compressing and stiffening the glenohumeral joint to counterbalance the larger muscles of the shoulder girdle during functional movement $[14 \bullet, 15]$. The supraspinatus acts a primary abductor of the humerus, whereas the infraspinatus and teres minor are primary external rotators of the glenohumeral joint. The subscapularis' primary function is internal rotation of the glenohumeral joint. A disruption or injury to any of the rotator cuff muscles can affect glenohumeral joint stability and disrupt normal shoulder kinematics.

\section{Classification}

Classification of a rotator cuff tear is important to guide treatment and to allow comparison between outcome studies. A tear may be classified based on size of the lesion, the number of tendons involved, and signal abnormality in the tendon on MRI. The initial distinction to make when evaluating rotator cuff tendon pathology in the elite athlete is to distinguish an acute, direct contusion from an underlying chronic process. Rotator cuff contusion is characterized by increased signal intensity in the tendon, but no tear (Fig. 1). Rotator cuff contusion can be distinguished from chronic tendonosis by the presence of increased signal in both the tendon and the overlying bursa, as well as frequent associated bone marrow edema pattern in the underlying tuberosity. There may be a fluid

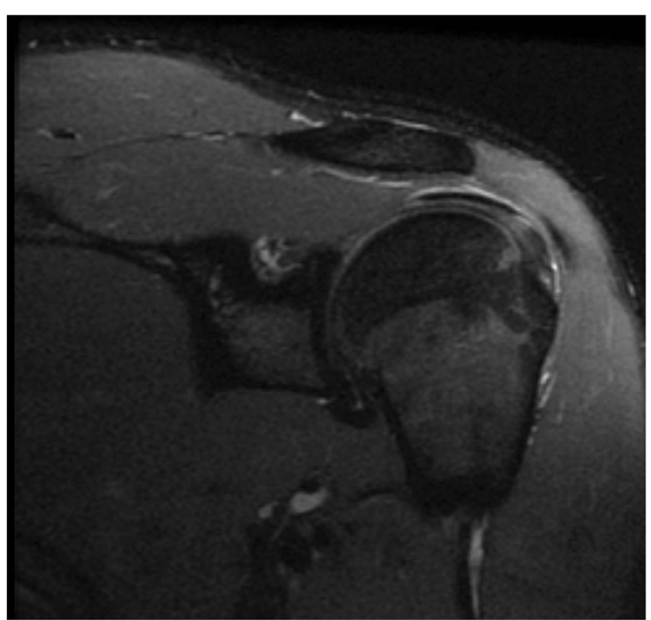

Fig. 1 Coronal magnetic resonance image of a left shoulder demonstrates contusion of the supraspinatus tendon

collection in the subacromial/sub-deltoid region, suggestive of a bleed from the acute contusion injury. The diagnosis of rotator cuff contusion is also suggested by the acute mechanism of injury, which is typically a direct blow to the shoulder from falling on the extremity or direct contact by another player.

Tendinopathy is characterized by abnormal signal intensity in the tendon on MRI. There may also be thickening of the tendon. Ultrasound will show loss of the normal echogenic structure of the tendon, due to collagen fiber disorganization. Changes in the rotator cuff tendon consistent with tendonosis are fairly common in athletes engaged in repetitive overhead activities, such as throwers, swimmers, and tennis players. Tendonosis can also develop in football players from years of heavy weight lifting exercises. Partial thickness tears may develop in tendons with underlying tendinosis with most partial thickness tears beginning on the articular side of the tendon in this setting (Fig. 2). Full thickness tears are less common in young athletes but may be seen after direct trauma. A full thickness tear in a young individual (such as an athlete) is often seen in the setting of pre-existing tendonosis (acute on chronic presentation).

\section{Clinical Presentation}

Clinical presentation of injuries to the rotator cuff can vary by type of injury and mechanism of onset. A thorough history that includes mechanism of injury and arm position at the time of injury can help the clinician determine the presence of injury to the rotator cuff [16]. Examination of the athlete should include thorough palpation and assessment of both active and passive range of motion. Athletes will often demonstrate a painful arc of active motion.

Overhead athletes with rotator cuff pathology may present with excessive passive external rotation and limited internal 


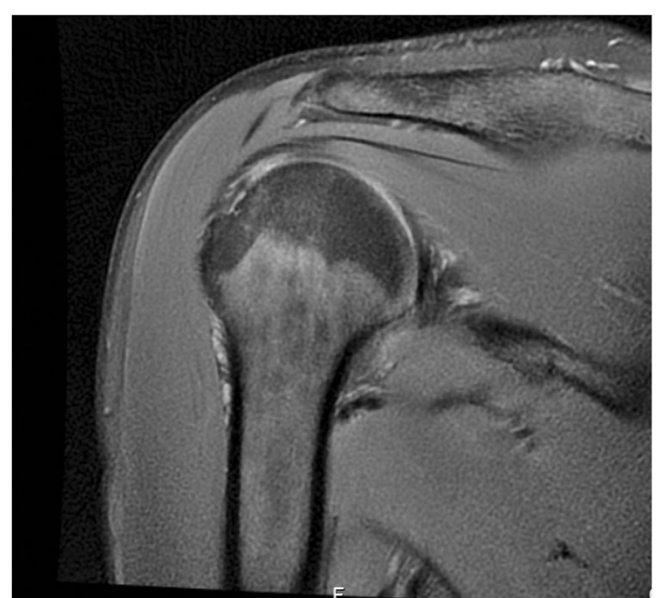

Fig. 2 Coronal magnetic resonance image of a right shoulder demonstrates a partial thickness infraspinatus tendon tear in an overhead throwing athlete

rotation (IR) at 90 degrees of glenohumeral abduction. This disparity, referred to as glenohumeral internal rotation deficit (GIRD), is a loss of IR in the dominant shoulder of 20 degrees or more as compared to the non-dominant shoulder, which can result from both muscular and capsular tightness [8, 17-19]. Furthermore, strength assessment should include both the shoulder and scapular musculature. This can help the clinician determine the level of muscular involvement and also assist with developing the post-injury rehabilitation protocol. An acute rotator cuff contusion can lead to transient reflex inhibition of the rotator cuff and deltoid, resulting in marked weakness. Glenohumeral stability should also be assessed. The cervical spine and elbow should be ruled out as a possible referral source for the shoulder pain.

Imaging includes plain radiographs to rule out bony injury, assess for pre-existing degenerative changes, and assess the position of the humeral head relative to the glenoid. Acute rotator cuff inhibition associated with a contusion may lead to transient loss of humeral head centering, with proximal migration of the humerus relative to the glenoid. MRI scan is the gold standard to assess the integrity of the rotator cuff tendon as well as the musculature. MRI also allows evaluation of the labrum and articular cartilage. Diagnostic ultrasound is also commonly used and is a reliable modality to assess rotator cuff injury and provides the benefit of allowing for a dynamic assessment. Particularly in the setting of elite athletes, it is beneficial to have a designated musculoskeletal radiologist who is experienced with athlete-specific pathology to partner with for such studies.

\section{Rehabilitation}

Conservative management of rotator cuff injuries should include a comprehensive rehabilitation program. Wilk and colleagues $[18 \cdot, 20,21]$ have extensively reported on shoulder rehabilitation for the throwing athlete with many of the same principles able to be applied to all types of athletes with varying patterns of rotator cuff injury. A recent review by Edwards et al. [14 $]$ provided an evidence-based 4-phase exercise protocol for the conservative management of rotator cuff injury. These phases included range of motion, flexibility, strengthening, and advanced strengthening/proprioception. Similar to the two aforementioned approaches, our belief is that the complete rehabilitation program should focus on eliminating initial pain and inflammation, improving shoulder mobility, and addressing stability, strength, power, and neuromuscular control, while correcting any identifiable issues along the kinematic chain. Program design should be progressive, functional, and sport-specific in efforts to best prepare the athlete for return-to-competition.

\section{Early Rehabilitation}

Early rehabilitation following rotator cuff injury should focus on the reduction of pain, inflammation, swelling, and restoring normal range of motion. This can be accomplished using both local physical modalities such as ice, electrical stimulation, and laser in addition to manual therapies. In a painful shoulder, studies have demonstrated a decrease in electromyographic activity by $23 \%$ with a corresponding reduction in external rotation force production by $32 \%$ [22]. This finding suggests the importance of early pain reduction such that the athlete can begin a progressive strengthening program. The athlete should also avoid activities that cause reproduction of symptoms. This may include activities related to weight training or sport-specific activities such as throwing.

Manual therapies such as joint mobilization and passive range of motion can assist with restoring normal joint kinematics and improving glenohumeral joint range motion. Glenohumeral joint grade I and grade II joint mobilization techniques can be performed not only to reduce pain but also to decrease muscle guarding in an effort to enhance the athletes' range of motion [23]. Additionally, one of the more common, remedial, and safe shoulder exercises to reduce joint stiffness and improve range of motion is the Codman's pendulum exercise [24]. Range of motion exercises can be progressed to active-assisted activities where patients can use a wand and their unaffected arm to move through the desired range of motion, followed by active, unassisted exercises.

Elite athletes with injuries to the rotator cuff may demonstrate limitations in glenohumeral range of motion that include GIRD and other deficiencies. Limitations, specifically with internal rotation in the overhead athlete, are often related to chronic tightness of the posterior rotator cuff, posterior shoulder musculature caused by poor position of the scapula, or the posterior joint capsule [18•]. Both the modified sleeper stretch as well as the modified cross-body stretch are two common exercises that have been shown to be effective for increasing shoulder internal rotation and horizontal adduction of the 
glenohumeral joint, respectively $[25,26 \bullet]$. Stretching of the pectoralis minor muscle may also be beneficial for improving scapular mechanics and overall shoulder function [27].

Intramuscular dry needling has also been shown to improve shoulder range of motion and function [28-31]. This technique involves a practitioner using fine filaform needle to penetrate the skin and underlying muscle to reduce both pain and spasm associated with tight muscles and myofascial trigger points. The underlying mechanism behind the use of dry needling is dependent upon the clinician's goals for treatment and also the type of tissue that is being treated [32]. For the treatment of chronic tendon injury, dry needling can be used to stimulate blood flow and subsequent growth factors that may assist with the healing process. In the presence of trigger points and muscle spasm, dry needling is used is to elicit a local twitch response, reduce nociceptive, inflammatory, and immune related chemicals, and relax the taut band of tissue [31]. A recent randomized controlled trial demonstrated that dry needling had therapeutic effects on supraspinatus lesions and improved shoulder range of motion [28]. Similarly, a study by Osborne and Gatt [30] demonstrated overall improved shoulder range of motion and function in elite volleyball players following treatment of the scapulohumeral musculature. While early results have been positive, further study is needed to determine the overall efficacy of this treatment modality in elite athletes with rotator cuff pathology.

From our clinical experience, utilizing aquatic therapy early in the rehabilitation process can assist with the restoration of active range of motion, normal shoulder kinematics, and preparing the shoulder for progression to land-based activities [33]. The properties of water, including viscosity and hydrostatic pressure, may also assist in providing resistance with exercise without having to use weights, and can also aid in the reduction of swelling.

Following injury, there may be muscle inhibition of the rotator cuff due to the post-injury pain and joint effusion. Neuromuscular electrical stimulation can be used shortly after injury to assist with neuromuscular re-education and muscle activation. This type of electrical stimulation has been shown to improve external rotation force production when applied to the infraspinatus following rotator cuff repair [34]. Isometric exercises are also a safe and effective way early in the rehabilitation process to promote muscle activation and lead into more advanced isotonic strengthening exercises.

\section{Intermediate Phase}

The intermediate phase of the rehabilitation process should include a progressive strengthening program focusing on the scapular musculature as well as the rotator cuff. The scapulothoracic joint and related scapular musculature provides a critical role in overall shoulder function. Therefore, rehabilitation programs should emphasize neuromuscular control focusing on enhancing proximal stability of this region prior to addressing distal segment mobility. The scapula provides a stable base that allows the humeral head to both elevate and rotate during functional activities. Furthermore, human movement and more specifically sports-related movement does not occur in isolation, but rather occurs in orchestrated interactions between many joints in multiple planes. Therefore, one of the essential roles of the scapulothoracic articulation is its ability to serve as a bridge between the core musculature and lower extremity as kinetic energy is transferred up the chain during sport-specific movements [13].

Altered scapular positioning, specifically anterior tilting, has been shown to limit glenohumeral joint internal rotation and is believed to contribute to multiple shoulder pathologies. Abnormal scapular kinematics and dysfunctional scapulohumeral rhythm can be caused by pain associated with injury, soft tissue tightness, strength imbalances, deficiencies in muscle activity, and resultant poor posture [35]. Previous studies have suggested that individuals with rotator cuff pathology and shoulder pain demonstrate decreased strength of the serratus anterior, early activation and hyperactivity of the upper trapezius, and decreased activity and activation of the middle and lower trapezius [14•, 36-38]. Developing intervention programs that target the serratus anterior and middle and lower trapezius, while minimizing upper trapezius activation, can enhance scapulohumeral rhythm and glenohumeral position in space, thus allowing better function of the rotator cuff during shoulder activities.

A progressive scapular strengthening program should include both open and closed kinetic chain activities (Figs.3 and 4). Closed kinetic chain exercises, such as the push-up plus, have been shown to generate higher muscle activation of the serratus anterior [39]. Exercises in the closed kinetic chain are believed to promote greater co-contraction between the rotator cuff and scapular stabilizers, stimulate joint mechanoreceptors, and better replicate the demands of certain sports, for example - an offensive lineman blocking in American Football or a collegiate wrestler working from the referee's position on the mat.

Isolated strengthening of the rotator cuff muscles should be included once pain and inflammation from the initial injury have subsided and is essential in maintaining centering of the humeral head on the glenoid fossa during functional activities. Numerous studies have used electromyographic analysis of the rotator cuff muscles to assist with the development of optimal post-injury treatment plans [15, 40, 41]. Studies have demonstrated that sidelying external rotation produces high EMG activity in both the infraspinatus and teres minor (Fig. 5) [41]. Wilk et al. [20] developed the "Thrower's 10" program, which is a progressive isotonic strengthening program based on EMG data that addresses both strengthening of the rotator cuff muscles and scapular stabilizers. These exercises can be advanced to be performed on a stability ball to enhance core activation and can be progressed to enhance 


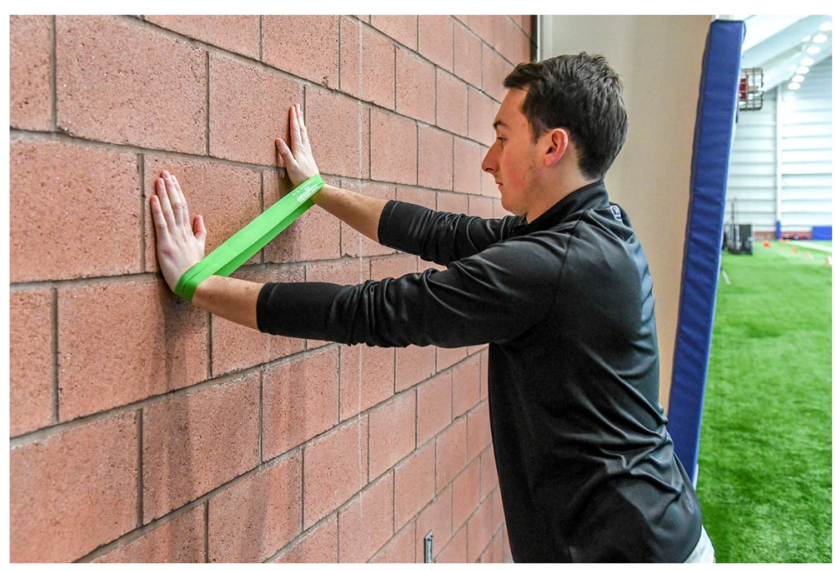

Fig. 3 Wall clock exercise to improve scapular stability

muscular endurance with alternating movements and sustained holds [21]. While developed for the overhead thrower, the principles of this program can be applied to most athletes recovering from an injury to the rotator cuff.

Blood flow restriction (BFR) training is a newer technique that can be employed during this stage and can be used as an adjunct to traditional resistance training. BFR requires an inflatable cuff to be placed proximally around a limb to create brief periods of partial venous occlusion while performing exercises between 20 and $40 \%$ of an individual's 1-repetition maximum [42]. BFR has been shown to provide similar muscular adaptations in the upper extremity such as hypertrophy and strength similar to that of higher load resistance training [43]. These findings include muscle groups proximal to the site of occlusion, including the chest, back, and shoulder. While early results of this technique appear promising, further research is needed to determine the mechanism and overall efficacy of this technique for athletes with rotator cuff injury.

\section{Advanced/Late Stage Rehabilitation}

Late stage rehabilitation should include advanced strengthening and endurance training, dynamic stabilization drills, and sport-

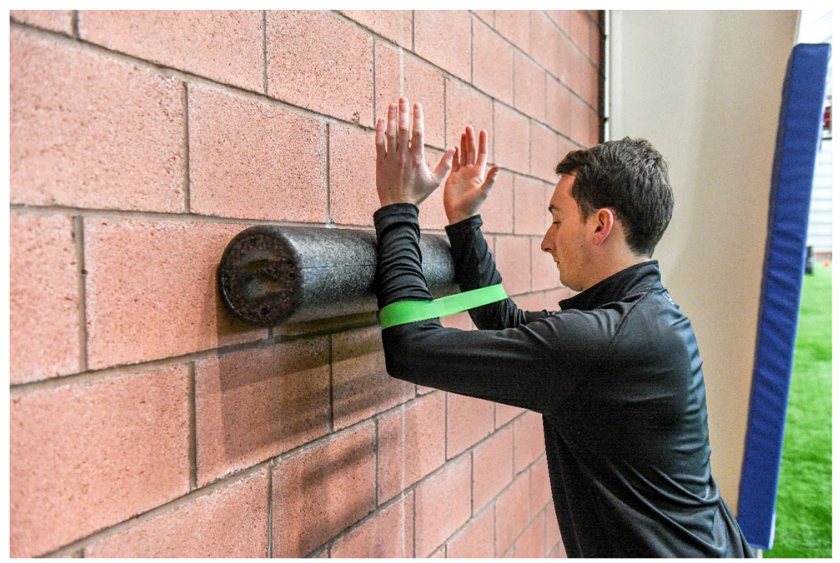

Fig. 4 Foam roller exercise to improve scapular stability

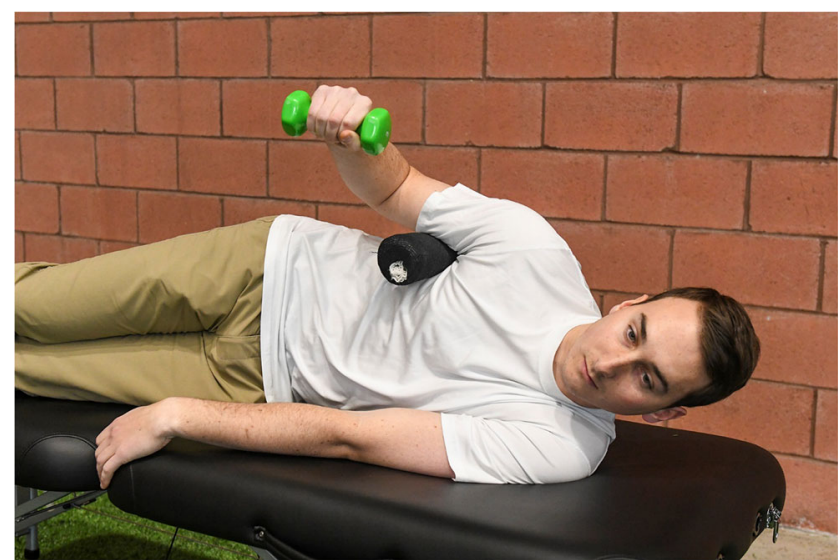

Fig. 5 Sidelying external rotation exercise to improve infraspinatus and teres minor strength

specific activities. Exercises in this stage should include drills specific to the demands of sport and an individual's position. The athlete should be progressed back into full weight training activities with careful collaboration between the medical, rehabilitation, and strength and conditioning staff. Strength training should address both upper body pulling exercises and upper body pressing exercises in addition to core stability.

Upper extremity plyometric exercises can be initiated and have been shown to be beneficial for improving proprioception, kinesthesia, as well as muscular endurance for the rotator cuff (Fig. 6) [44]. Plyometric exercises involve three distinct phases: an eccentric pre-stretch, followed by the amortization phase, which is then followed by a concentric contraction. The

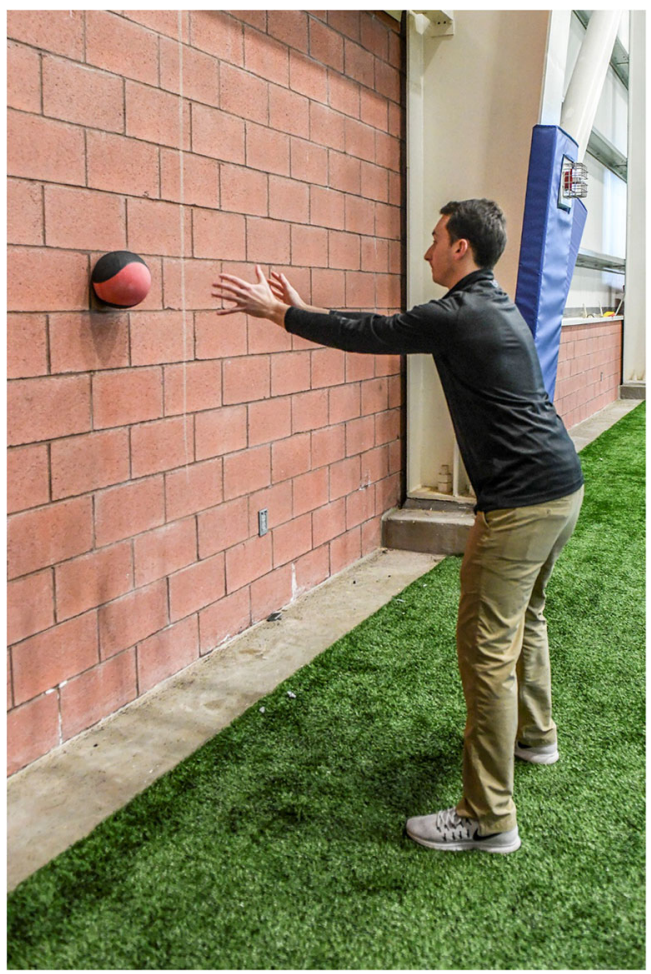

Fig. 6 Plyometric chest pass with a medicine ball 
amortization phase, which is defined as the time between the eccentric and concentric phases, should be as short as possible to allow for adequate energy transfer. Plyometric exercises for the upper extremity usually include throws that can be progressed from two-handed to one-handed drills, while being performed in a variety of conditions (tall knee, half kneel, unstable surface). Rhythmic stabilization exercises, while they can be initiated early in the rehabilitation program, can be progressed to more complex exercises to include unstable surfaces and performance on a physioball to improve overall neuromuscular control.

For the overhead thrower, a throwing program can be initiated and should include a graded training, carefully monitoring quantity of throws, distance, intensity, and types of throws [45].

\section{Medical Management}

\section{Non-Steroidal Anti-inflammatory Medication}

Judicious use of oral non-steroidal anti-inflammatory drugs (NSAIDS) can be used in the short term to assist with postinjury pain and inflammation associated with rotator cuff injury. These should be used with caution as long-term NSAID use has been associated with gastrointestinal illness and elevated cardiovascular risk. A recent meta-analysis that examined the use of oral NSAIDs on rotator cuff tendinopathy demonstrated that these medications may be effective in reducing short-term pain and can be as effective as corticosteroid injection to improve short-term pain and function [46].

\section{Corticosteroid Injection}

Corticosteroid injections are widely used in orthopedics and traditionally have been the cornerstone injection therapy in a variety of shoulder conditions [47]. In the young athlete, however, caution must be exercised with repeated corticosteroid injections for rotator cuff disease due to the risk of tendon weakening and rupture [48, 49]. Frequently used corticosteroids are methylprednisolone and triamcinolone, which are thought to have equivalent potency, followed by betamethasone and dexamethasone, which are proportionally more potent than both methylprednisolone and triamcinolone and thus are administered in smaller doses [47, 50, 51]. There are limited studies on the use of corticosteroid injection for rotator cuff disease in elite athletes. In a retrospective study of 26 professional football players with a rotator cuff contusion, six players had persistent pain and shoulder dysfunction at 3 days and were given a subacromial corticosteroid injection to assist in their recovery [4]. During the first 3 days after injury, all players received Darvocet, range of motion therapy, cryotherapy, interferential stimulation, and pulsed ultrasound; no NSAIDs were used. Only one of the six players who received a subacromial injection went on to later surgical treatment, although it was unclear whether this player underwent surgery for rotator cuff repair or labral repair. In another study of 43 young athletes (more than half collegiate or professional) with partial rotator cuff tears, 7 of 14 athletes who sustained acute, traumatic injuries and 11 of 29 overhead athletes who had an insidious, atraumatic onset of pain had at least one subacromial corticosteroid injection, which provided temporary pain relief in 57 and $36 \%$ of athletes in each group, respectively [10]. However, all athletes in this study failed nonoperative management and required operative treatment due to continued shoulder pain that precluded them from returning to sport.

Some randomized trials in the general population have reported efficacy of subacromial corticosteroid injection for reducing pain, increasing range of motion, and improving function over placebo in patients with rotator cuff disease [52-54]. However, other studies have reported no statistical differences in pain scores, range of motion, or functional scores compared to placebo [55-59]. A Cochrane systematic review comparing steroid injections and concomitant oral NSAIDs to NSAIDs alone reported no difference in pain, function, and abduction range of motion at various time points [50].

\section{Prolotherapy}

Prolotherapy, or hypertonic dextrose injection, has been described for treatment of chronic painful rotator cuff tendinopathy [60]. Although the exact mechanism of this type of treatment remains unclear, it is thought that injection of an irritant solution at painful ligament and tendon insertions stimulates local healing by inducing an inflammatory response and subsequent proliferation of new tissue, which is typically a scar tissue response [61]. Most of the literature on prolotherapy is limited to the treatment of knee osteoarthritis, and the literature on prolotherapy in the shoulder is limited to small retrospective series outside of North America. Lee et al. conducted a retrospective case-control study among a heterogeneous Korean population with rotator cuff disease showing that prolotherapy injection led to improvement in VAS score, Shoulder Pain and Disability Index (SPADI) score, isometric strength, and active ROM compared to continued conservative management without injection [62]. A similar study conducted in a Turkish population by Seven et al. showed similar results with improvement in VAS, SPADI, and Western Ontario Rotator Cuff (WORC) Index at up to 1 year in patients treated with prolotherapy versus no injection [63]. To our knowledge, there are no studies of prolotherapy for rotator cuff disease specifically in athletes, and there are no studies comparing prolotherapy to other injection therapies. Given that prolotherapy can incite an inflammatory response, its use would not be indicated in the acute phase of rotator cuff contusion. 


\section{Platelet-Rich Plasma Injection}

Platelet-rich plasma (PRP) injections locally deliver high concentrations of biologic factors essential to the healing process to augment musculoskeletal tissue repair. Due to its accessibility as an autologous "minimally manipulated" biologic treatment product, the use of PRP has gained substantial popularity for the treatment of various orthopedic conditions in the elite athlete. To our knowledge, there are no studies of PRP injection specifically in athletes for rotator cuff disease; however, several level I studies report no difference in clinical outcomes in patients who received PRP injection for rotator cuff tendinopathy compared to controls $[64,65]$. It is important to note that there remains substantial variability in the methods of PRP production among commercial systems [66-68]. Additionally, within a given PRP preparation protocol, there is a high degree of inter- and intra-subject variability in the composition of PRP produced [69]. This variability makes it difficult to draw any definitive conclusions on the efficacy of PRP treatment for rotator cuff disease.

\section{Return-to-Competition}

As with any sports-related injury, decisions on return-tocompetition following injury to the rotator cuff should be made collaboratively with the team physician, rehabilitation staff, and the athlete. The decision should be predicated on physical exam findings consistent with pre-injury levels of pain, range of motion, stability, strength, and overall shoulder function. The athlete should demonstrate adequate power and muscular endurance and be able to satisfactorily perform all that is required based on the demands of their sport. It is recommended that the return to team-related activities and training should be step-wise and titrated accordingly. For example, in American Football, often a player will be returned to individual position drills first, followed by unit drills (offense/ defense), and finally full team activities without restrictions. For overhead throwers, this may include monitoring pitch count, or for swimmers modification of distance and stroke.

In collision and contact sports, such as American Football, soccer, and lacrosse, the medical staff may consider using offthe-shelf bracing options to assist with limiting shoulder range of motion and avoiding positions that may cause pain and prevent re-injury. Hard-shell padding can be used in the presence of previous rotator cuff contusions to avoid a second direct contact. Upon return-to-competition, the athlete should be carefully monitored to avoid a repeat injury.

\section{Surgical Options}

While non-operative management is the first line treatment for most rotator cuff tears, operative intervention can be considered when the patient fails to respond to conservative measures. Operative treatment of the rotator cuff can be performed in several ways, and the choice is dependent on several factors including surgeon experience and preference, characteristics of the tear and patient-specific factors such as age, sport, and position. The surgical approach to the repair of the rotator cuff can be performed open, mini-open (arthroscopically assisted), or arthroscopically [70]. There is limited evidence supporting one approach over another, but arthroscopic repair has steadily gained in popularity along with the improvements in arthroscopic technique and avoids many of the complications associated with open surgery including deltoid compromise, higher nerve injury rate, increased postoperative pain, increased infection rate, and joint stiffness.

While previous studies demonstrate repair of the rotator cuff to alleviate pain and improve function in the general population, there is a paucity of evidence regarding the treatment and outcomes of these procedures in high-level athletes. The primary expectation of the athlete following surgical repair is to return to sport at the same pre-injury level of play. Dines et al. demonstrated that debridement alone without repair of small, partial-thickness tears allowed the majority of elite throwing athletes to return to competitive pitching, yet returning them to their previous level of competition was a challenge for many of the players [71•]. Furthermore, Reynolds et al. reported that partial thickness rotator cuff tears treated with debridement alone allowed the majority of elite overhead throwing athletes to return to competitive pitching (76\%), but returning to their previous level of play remained a challenge (55\%) [72].

Klouche et al. reported a systematic review and metaanalysis of the rate of return to sport after surgical treatment of rotator cuff tears and found that the overall rate of return to sport was $84.7 \%$, with $65.9 \%$ at equivalent level of play, but only $49.9 \%$ of the professional and competitive athletes returning to same level of play [73•]. Conway reported an $89 \%$ return to the same or higher level of play following a partial rotator cuff repair in a sample of 14 high-level baseball players [74].

Return to same level of play after surgical repair of full thickness tears in overhead athletes in professional baseball athletes has been unpredictable and can potentially be career ending injuries $[75,76]$. Dines et al. demonstrated that arthroscopic repair of full thickness tears in professional baseball players allowed $83 \%$ to return to pre-injury level of competition, but despite high rate of return to Major League Baseball, few resumed pitching at the same level, and performance almost uniformly decreased [71•]. Arthroscopic shoulder surgery for rotator cuff and/or the labrum was performed in professional female tennis players, with only $25 \%$ of players achieving their pre-injury singles rank or better, with $88 \%$ returning to professional play [77]. 
In regards to the contact athlete, a survey of National Football League (NFL) team physicians demonstrated 51 full thickness rotator cuff tears in 49 players over the 10 -year study period. Of those injuries reported, all but four required surgical repair [78]. Tampe et al. reported on arthroscopic rotator cuff repair in professional rugby players. Of the 11 players who were injured in the 2-year study period and underwent arthroscopic repair, all returned to their previous level of sport on average at 4.8 months [79].

In summary, the surgical management of the rotator cuff injury in the high-demand athlete is a challenging problem and the limited data available has reported less than optimal clinical outcomes, demonstrating the need for further research in this area. Therefore, it is important to communicate with the patient a realistic understanding of the expectations, and the real possibility that an injury requiring surgery may prevent one from returning to the same level of competition [80].

\section{Future Directions}

The underlying cellular and molecular mechanisms that lead to tendonopathy are poorly understood. This has contributed to our lack of effective treatments for degenerative tendonopathy. Furthermore, tendon healing after repair is a slow and imperfect process. The structure and composition of the native rotator cuff tendon insertion site are not reformed following surgical repair. Research in this field is currently focused on understanding the underlying molecular mediators that are responsible for degenerative tendinopathy, and that initiate and regulate the tendon healing process. As we gain improved understanding of the biological events in tendon degeneration and tendon healing, this data will presumably suggest avenues for "biological augmentation" of tendon repair.

Current options for biologic augmentation include injection of PRP and the use of cell-based therapy. The rationale for the use of PRP is the ability to provide numerous cytokines, growth factors, and other platelet-derived and plasmaderived proteins that can increase cell proliferation, matrix synthesis, and angiogenesis. However, there is currently limited data to suggest that PRP is effective in treatment of tendinopathy or tendon healing. One of the fundamental limitations of PRP therapy is the significant inter-individual variability in the composition and biologic activity. Further work is required to understand the specific factors in PRP that may have a positive effect on tendon biology.

Cell-based approaches ("stem cells") also appear to have great potential for improvement of tendon healing. The basic options at this time for stem cell therapy include cells derived from bone marrow and adipose tissue. However, the number of true stem cells by formal molecular criteria is very low in these tissues. Furthermore, current FDA regulations do not allow cell sorting and culturing in order to expand the number of stem cells. As a result, our current ability to apply stem cells to healing tendon is limited. Similar to PRP, there is significant inter-individual variability in the number and biological activity of stem cells harvested from various tissues. All of these factors contribute to our current limited ability to use cells for biologic augmentation of tendon.

Promising approaches in the area of stem cell research include the potential to use induced pluripotent stem cells (iPSC's) and the possibility of stimulating the endogenous stem cells ("intrinsic stem cell niche") that are known to be present in many tissues, including tendon. Induced pluripotent stem cells are created using gene therapy techniques to "reprogram" a differentiated cell (such as a cell derived from blood or skin) such that it is equivalent to an undifferentiated embryonic stem cell. Although this approach has exciting potential for biological augmentation of tendon, there are currently scientific, logistical, and safety hurdles to overcome before this approach can be used in orthopedic applications.

The intrinsic stem cell niche refers to the small population of quiescent progenitor cells that are known to be present in many tissues, including tendon. These are cells that likely participated in embryologic tendon development. The challenge at this time is to identify the factors that regulate and control these intrinsic progenitor cells, so that we could eventually leverage these cells for tendon healing.

As ongoing research provides further insight into the biology of tendon degeneration, healing, and repair, signaling pathways may be identified that can suggest avenues for development of novel pharmacologic agents and other approaches to improve tendon healing.

\section{Conclusion}

Injuries to the rotator cuff remain a common cause of pain and dysfunction for the elite athlete and can result in time loss from participation. Management of rotator cuff injuries in the elite athlete provides many challenges for the sports medicine staff. These injuries can be managed both non-surgically and surgically; however, optimal management is predicated on a myriad of factors related to both the underlying pathology and also sport-related variables including the athlete's position and time of the season. Based on our experience, many of these injuries can be managed conservatively in-season with anti-inflammatories, injection, and a comprehensive rehabilitation program. Those rotator cuff tears that do not respond to conservative management can be addressed operatively in the off-season or immediately based on the athlete's current level of dysfunction and ability to meet the demands of their sport.

The management of rotator cuff injuries in the elite athlete will continue to be guided by advances in basic science, clinical research, and clinician acumen. Newer treatment 
techniques such as intramuscular dry needling, blood flow restriction therapy, and the use of biologics are supported by some early data but require more level I studies to determine their effectiveness in the treatment of rotator cuff injuries. An early and accurate diagnosis followed by an individualized and comprehensive treatment program will afford the sports medicine staff the greatest opportunity to return the elite athlete back to competition following rotator cuff injury both expediently and safely.

\section{Compliance with Ethical Standards}

Conflicts of Interest Leigh Weiss, Scott Rodeo, Dean Wang, Michael Hendel, Philip Buzzerio declare that they have no conflict of interest.

Human and Animal Rights This article does not contain any studies with human or animal subjects performed by the authors.

\section{References}

Papers of particular interest, published recently, have been highlighted as:

- Of importance

1. Namdari S, Baldwin K, Ahn A, Huffman GR, Sennett BJ. Performance after rotator cuff tear and operative treatment: a case-control study of major league baseball pitchers. J Athl Train. 2011;46(3):296-302. https://doi.org/10.4085/1062-6050-46.3.296.

2. Blevins FT, Hayes WM, Warren RF. Rotator cuff injury in contact athletes. Am J Sports Med. 1996;24(3):263-7. https://doi.org/10. 1177/036354659602400303.

3. Mueller M, Hoy G, Branson R. Management of in-Season Concurrent Rotator Cuff Tear with Shoulder Instability in professional contact football athletes; respect the career goals! Asian journal of sports medicine. 2016;7(1):e28377. https://doi.org/10.5812/ asjsm. 28377.

4. Cohen SB, Towers JD, Bradley JP. Rotator cuff contusions of the shoulder in professional football players: epidemiology and magnetic resonance imaging findings. Am J Sports Med. 2007;35(3): 442-7. https://doi.org/10.1177/0363546506295082.

5. Kaplan LD, Flanigan DC, Norwig J, Jost P, Bradley J. Prevalence and variance of shoulder injuries in elite collegiate football players. Am J Sports Med. 2005;33(8):1142-6. https://doi.org/10.1177/ 0363546505274718.

6. Gibbs DB, Lynch TS, Gombera MM, Saltzman MD, Nuber GW, Schroeder GD, et al. Preexisting rotator cuff tears as a predictor of outcomes in National Football League Athletes. Sports health. 2016;8(3):250-4. This study reports that players with a preexisting rotator cuff tear were less likely to be drafted into the National Football League and had shorter career longevity when compared to controls. https://doi.org/10.1177/ 1941738116636602.

7. Matava MJ, Purcell DB, Rudzki JR. Partial-thickness rotator cuff tears. Am J Sports Med. 2005;33(9):1405-17. https://doi.org/10. 1177/0363546505280213.

8. Burkhart SS, Morgan CD, Kibler WB. The disabled throwing shoulder: spectrum of pathology part II: evaluation and treatment of SLAP lesions in throwers. Arthroscopy: The Journal of
Arthroscopic \& Related Surgery. 2003;19(5):531-9. https://doi. org/10.1053/jars.2003.50139.

9. Burkhart SS, Morgan CD, Kibler WB. The disabled throwing shoulder: spectrum of pathology part I: pathoanatomy and biomechanics. Arthroscopy: The Journal of Arthroscopic \& Related Surgery. 2003;19(4):404-20. https://doi.org/10.1053/jars.2003. 50128.

10. Payne LZ, Altchek DW, Craig EV, Warren RF. Arthroscopic treatment of partial rotator cuff tears in young athletes: a preliminary report. Am J Sports Med. 1997;25(3):299-305. https://doi.org/10. 1177/036354659702500305.

11. Carvalho CD, Cohen C, Belangero PS, Figueiredo EA, Monteiro GC, de Castro Pochini A, et al. Partial rotator cuff injury in athletes; bursal or articular. Rev Bras Ortop. 2015;50(4):416-21. https://doi. org/10.1016/j.rbo.2014.07.002.

12. Miniaci A, Mascia AT, Salonen DC, Becker EJ. Magnetic resonance imaging of the shoulder in asymptomatic professional baseball pitchers. Am J Sports Med. 2002;30(1):66-73. https://doi.org/ 10.1177/03635465020300012501.

13. Braun S, Kokmeyer D, Millett PJ. Shoulder injuries in the throwing athlete. JBJS. 2009 Apr 1;91(4):966-78. https://doi.org/10.2106/ JBJS.H.01341.

14. Edwards P, Ebert J, Joss B, Bhabra G, Ackland T, Wang A. Exercise rehabilitation in the non-operative management of rotator cuff tears: a review of the literature. International. This clinical commentary examines the available evidence for conservative management, specifically rehabilitation, of rotator cuff tears.

15. Escamilla RF, Yamashiro K, Paulos L, Andrews JR. Shoulder muscle activity and function in common shoulder rehabilitation exercises. Sports Med. 2009 Aug 1;39(8):663-85. https://doi.org/10. 2165/00007256-200939080-00004.

16. Gibbs DB, Lynch TS, Nuber ED, Nuber GW. Common shoulder injuries in American football athletes. Current sports medicine reports. $2015 ; 14(5): 413-9$. https://doi.org/10.1249/JSR. 0000000000000190 .

17. Kibler WB, Kuhn JE, Wilk K, Sciascia A, Moore S, Laudner K, et al. The disabled throwing shoulder: spectrum of pathology-10year update. Arthroscopy: the journal of arthroscopic \& related surgery. 2013;29(1):141-61. https://doi.org/10.1016/j.arthro.2012. 10.009 .

18. Wilk KE, Williams RA, Dugas JR, Cain EL, Andrews JR. Current concepts in the assessment and rehabilitation of the Thrower's shoulder. Operative Techniques in Sports Medicine. 2016;24(3): 170-80. This study discusses a comprehensive 4-phase approach to rehabilitation of the throwing athlete. https://doi.org/ 10.1053/j.otsm.2016.04.004.

19. Burkhart SS, Morgan CD, Kibler WB. The disabled throwing shoulder: spectrum of pathology part III: the SICK scapula, scapular dyskinesis, the kinetic chain, and rehabilitation. Arthroscopy: The Journal of Arthroscopic \& Related Surgery. 2003;19(6):64161. https://doi.org/10.1016/S0749-8063(03)00389-X.

20. Wilk KE, Andrews JR, Arrigo CA. Preventive and rehabilitative exercises for the shoulder and elbow. American Sports Medicine Institute. 6th ed. Birmingham, AL.

21. Wilk KE, Yenchak AJ, Arrigo CA, Andrews JR. The advanced throwers ten exercise program: a new exercise series for enhanced dynamic shoulder control in the overhead throwing athlete. Phys Sportsmed. 2011;39(4):90-7. https://doi.org/10.3810/psm.2011.11. 1943.

22. Stackhouse SK, Eisennagel A, Eisennagel J, Lenker H, Sweitzer BA, McClure PW. Experimental pain inhibits infraspinatus activation during isometric external rotation. J Shoulder Elb Surg. 2013;22(4):478-84. https://doi.org/10.1016/j.jse.2012.05.037.

23. Maitland GD. Vetebral. 4th ed. Boston: Butterworth; 1977. 
24. Codman EA. The shoulder: rupture of the supraspinatus tendon and other lesions in or about the subacromial Bursa. Malabar: G. Miller and Co Medical Publishers, Inc; 1984.

25. Wilk KE, Hooks TR, Macrina LC. The modified sleeper stretch and modified cross-body stretch to increase shoulder internal rotation range of motion in the overhead throwing athlete. J Orthop Sports Phys Ther. 2013;43(12):891-4. https://doi.org/10.2519/jospt.2013. 4990.

26. Yamauchi T, Hasegawa S, Nakamura M, Nishishita S, Yanase K, Fujita K, et al. Effects of two stretching methods on shoulder range of motion and muscle stiffness in baseball players with posterior shoulder tightness: a randomized controlled trial. J Shoulder Elb Surg. 2016;25(9):1395-403. This study demonstrates the efficacy of the modified sleep stretch and modified cross body stretch for increasing shoulder internal rotation and horizontal adduction. https://doi.org/10.1016/j.jse.2016.04.025.

27. Morais N, Cruz J. The pectoralis minor muscle and shoulder movement-related impairments and pain: rationale, assessment and management. Physical Therapy in Sport. 2016;17:1-3. https://doi.org/10.1016/j.ptsp.2015.10.003.

28. Rha DW, Park GY, Kim YK, Kim MT, Lee SC. Comparison of the therapeutic effects of ultrasound-guided platelet-rich plasma injection and dry needling in rotator cuff disease: a randomized controlled trial. Clin Rehabil. 2013;27(2):113-22. https://doi.org/10. $1177 / 0269215512448388$

29. Saylor-Pavkovich E. Strength exercises combined with dry needling with electrical stimulation improve pain and function in patients with chronic rotator cuff tendinopathy: a retrospective case series. International journal of sports physical therapy. 2016;11(3): 409-22.

30. Osborne NJ, Gatt IT. Management of shoulder injuries using dry needling in elite volleyball players. Acupunct Med. 2010;28(1):425. https://doi.org/10.1136/aim.2009.001560.

31. Passigli S, Plebani G, Poser A. Acute effects of dry needling on posterior shoulder tightness. A case report. International journal of sports physical therapy. 2016;11(2):254-63.

32. American Physical Therapy Association. Description of dry needling in clinical practice: an educational resource paper. APTA Public Policy, Practice and Professional Affairs Unit. 2013. Available from: http://www.apta.org/StateIssues/DryNeedling/ ClinicalPracticeResourcePaper/

33. Binkley H, Schroyer T. Aquatic therapy in the treatment of upper extremity injuries. Athletic. Therapy Today. 2002;7(1):49-54. https://doi.org/10.1123/att.7.1.49.

34. Reinold MM, Macrina LC, Wilk KE, Dugas JR, Cain EL, Andrews JR. The effect of neuromuscular electrical stimulation of the infraspinatus on shoulder external rotation force production after rotator cuff repair surgery. Am J Sports Med. 2008;36(12):231721. https://doi.org/10.1177/0363546508322479.

35. Ludewig PM, Reynolds JF. The association of scapular kinematics and glenohumeral joint pathologies. J Orthop Sports Phys Ther. 2009;39(2):90-104. https://doi.org/10.2519/jospt.2009.2808.

36. Cools AM, Struyf F, De Mey K, Maenhout A, Castelein B, Cagnie B. Rehabilitation of scapular dyskinesis: from the office worker to the elite overhead athlete. Br J Sports Med. 2013:bjsports-2013.

37. Page P. Shoulder muscle imbalance and subacromial impingement syndrome in overhead athletes. International journal of sports physical therapy. 2011;6(1):51-8.

38. Ellenbecker TS, Cools A. Rehabilitation of shoulder impingement syndrome and rotator cuff injuries: an evidence-based review. Br J Sports Med. 2010;44(5):319-27. https://doi.org/10.1136/bjsm. 2009.058875.

39. Decker MJ, Hintermeister RA, Faber KJ, Hawkins RJ. Serratus anterior muscle activity during selected rehabilitation exercises. Am J Sports Med. 1999;27(6):784-91. https://doi.org/10.1177/ 03635465990270061601.
40. Alizadehkhaiyat O, Hawkes DH, Kemp GJ, Frostick SP. Electromyographic analysis of shoulder girdle muscles during common internal rotation exercise. International journal of sports physical therapy. 2015;10(5):645-54.

41. Reinold MM, Wilk KE, Fleisig GS, Zheng N, Barrentine SW, Chmielewski T, et al. Electromyographic analysis of the rotator cuff and deltoid musculature during common shoulder external rotation exercises. J Orthop Sports Phys Ther. 2004;34(7):385-94. https:// doi.org/10.2519/jospt.2004.34.7.385.

42. Scott BR, Loenneke JP, Slattery KM, Dascombe BJ. Exercise with blood flow restriction: an updated evidence-based approach for enhanced muscular development. Sports Med. 2015;45(3):31325 . Recent review that examines the evidence and technique behind blood flow restriction training. https://doi.org/10.1007/ s40279-014-0288-1.

43. Dankel SJ, Jessee MB, Abe T, Loenneke JP. The effects of blood flow restriction on upper-body musculature located distal and proximal to applied pressure. Sports Med. 2016;46(1):23-33. https:// doi.org/10.1007/s40279-015-0407-7.

44. Swanik KA, Lephart SM, Swanik CB, Lephart SP, Stone DA, FH F. The effects of shoulder plyometric training on proprioception and selected muscle performance characteristics. J Shoulder Elb Surg. 2002;11(6):579-86. https://doi.org/10.1067/mse.2002.127303.

45. Reinold MM, Wilk KE, Reed J, Crenshaw K, Andrews JR. Interval sport programs: guidelines for baseball, tennis, and golf. J Orthop Sports Phys Ther. 2002;32(6):293-8. https://doi.org/10.2519/jospt. 2002.32.6.293.

46. Boudreault J, Desmeules F, Roy JS, Dionne C, Frémont P, MacDermid JC. The efficacy of oral non-steroidal anti-inflammatory drugs for rotator cuff tendinopathy: a systematic review and meta-analysis. J Rehabil Med. 2014;46(4):294-306. https://doi.org/ 10.2340/16501977-1800.

47. Koester MC, Dunn WR, Kuhn JE, Spindler KP. The efficacy of subacromial corticosteroid injection in the treatment of rotator cuff disease: a systematic review. J Am Acad Orthop Surg. 2007;15(1): 3-11. https://doi.org/10.5435/00124635-200701000-00002.

48. Schneeberger AG, Nyffeler RW, Gerber C. Structural changes of the rotator cuff caused by experimental subacromial impingement in the rat. J Shoulder Elb Surg. 1998;7(4):375-80. https://doi.org/ 10.1016/S1058-2746(98)90026-X.

49. Wei AS, Callaci JJ, Juknelis D, Marra G, Tonino P, Freedman KB, et al. The effect of corticosteroid on collagen expression in injured rotator cuff tendon. J Bone Joint Surg Am. 2006;88(6):1331-8. https://doi.org/10.2106/JBJS.E.00806.

50. Buchbinder R, Green S, Youd JM. Corticosteroid injections for shoulder pain. Cochrane Database Syst Rev. 2003(1):Cd004016.

51. Schimmer BP, Parker KL. Adrenocorticotropic hormone, adrenocortical steroids and their synthetic analogs; inhibitors of the synthesis and actions of adrenocortical hormones. In: Hardman JG, Limbird LE, editors. Goodman and Gillman's the Parmacological basis of therapeutics. 10th ed. New York: McGraw-Hill; 2001. p. 1649-78.

52. Adebajo AO, Nash P, Hazleman BLA. Prospective double blind dummy placebo controlled study comparing triamcinolone hexacetonide injection with oral diclofenac $50 \mathrm{mg}$ TDS in patients with rotator cuff tendinitis. J Rheumatol. 1990;17(9):1207-10.

53. Blair B, Rokito AS, Cuomo F, Jarolem K, Zuckerman JD. Efficacy of injections of corticosteroids for subacromial impingement syndrome. J Bone Joint Surg Am. 1996;78(11):1685-9. https://doi.org/ 10.2106/00004623-199611000-00007.

54. Petri M, Dobrow R, Neiman R, Whiting-O'keefe Q, Seaman WE. Randomized, double-blind, placebo-controlled study of the treatment of the painful shoulder. Arthritis Rheum. 1987;30(9):1040 5. https://doi.org/10.1002/art.1780300911.

55. Alvarez CM, Litchfield R, Jackowski D, Griffin S, Kirkley AA. Prospective, double-blind, randomized clinical trial comparing 
subacromial injection of betamethasone and xylocaine to xylocaine alone in chronic rotator cuff tendinosis. Am J Sports Med. 2005;33(2):255-62. https://doi.org/10.1177/0363546504267345.

56. McInerney JJ, Dias J, Durham S, Evans A. Randomised controlled trial of single, subacromial injection of methylprednisolone in patients with persistent, post-traumatic impingment of the shoulder. Emerg Med J. 2003;20(3):218-21. https://doi.org/10.1136/emj.20. 3.218 .

57. Mohamadi A, Chan JJ, Claessen FM, Ring D, Chen NC. Corticosteroid injections give small and transient pain relief in rotator cuff tendinosis: a meta-analysis. Clin Orthop Relat Res. 2017;475(1):232-43. https://doi.org/10.1007/s11999-016-5002-1.

58. Vecchio PC, Hazleman BL, King RH. A double-blind trial comparing subacromial methylprednisolone and lignocaine in acute rotator cuff tendinitis. Br J Rheumatol. 1993;32(8):743-5. https://doi.org/ 10.1093/rheumatology/32.8.743.

59. Withrington RH, Girgis FL, Seifert MHA. Placebo-controlled trial of steroid injections in the treatment of supraspinatus tendonitis. Scand J Rheumatol. 1985;14(1):76-8. https://doi.org/10.3109/ 03009748509102022

60. Bertrand H, Reeves KD, Bennett CJ, Bicknell S, Cheng AL. Dextrose Prolotherapy versus control injections in painful rotator cuff tendinopathy. Arch Phys Med Rehabil. 2016;97(1):17-25. https://doi.org/10.1016/j.apmr.2015.08.412.

61. Rabago D, Patterson JJ, Mundt M, Kijowski R, Grettie J, Segal NA, et al. Dextrose Prolotherapy for knee osteoarthritis: a randomized controlled trial. Ann Fam Med. 2013;11(3):229-37. https://doi.org/ 10.1370/afm.1504.

62. Lee DH, Kwack KS, Rah UW, Yoon SH. Prolotherapy for refractory rotator cuff disease: retrospective case-control study of 1-year follow-up. Arch Phys Med Rehabil. 2015;96(11):2027-32. https:// doi.org/10.1016/j.apmr.2015.07.011.

63. Seven MM, Ersen O, Akpancar S, Ozkan H, Turkkan S, Yıldız Y, et al. Effectiveness of prolotherapy in the treatment of chronic rotator cuff lesions. Orthop Traumatol Surg Res. 2017;103(3):42733. https://doi.org/10.1016/j.otsr.2017.01.003.

64. Carr AJ, Murphy R, Dakin SG, Rombach I, Wheway K, Watkins B, et al. Platelet-rich plasma injection with arthroscopic Acromioplasty for chronic rotator cuff tendinopathy: a randomized controlled trial. Am J Sports Med. 2015;43(12):2891-7. https://doi. org $/ 10.1177 / 0363546515608485$.

65. Kesikburun S, Tan AK, Yilmaz B, Yasar E, Yazicioglu K. Plateletrich plasma injections in the treatment of chronic rotator cuff tendinopathy: a randomized controlled trial with 1-year follow-up. Am J Sports Med. 2013;41(11):2609-16. https://doi.org/10.1177/ 0363546513496542.

66. Castillo TN, Pouliot MA, Kim HJ, Dragoo JL. Comparison of growth factor and platelet concentration from commercial plateletrich plasma separation systems. Am J Sports Med. 2011;39(2):26671. https://doi.org/10.1177/0363546510387517.

67. Degen RM, Bernard JA, Oliver KS, Dines JS. Commercial separation systems designed for preparation of platelet-rich plasma yield differences in cellular composition. HSS J. 2017;13(1):75-80. https://doi.org/10.1007/s11420-016-9519-3.

68. JH O, Kim W, Park KU, Roh YH. Comparison of the cellular composition and cytokine-release kinetics of various platelet-rich plasma preparations. Am J Sports Med. 2015;43(12):3062-70.

69. Mazzocca AD, McCarthy MB, Chowaniec DM, et al. Platelet-rich plasma differs according to preparation method and human variability. J Bone Joint Surg Am. 2012;94(4):308-16. https://doi.org/10. 2106/JBJS.K.00430.

70. Dodson CC, Brockmeier SF, Altchek DW. Partial-thickness rotator cuff tears in throwing athletes. Operative Techniques in Sports Medicine. 2007;15(3):124-31. https://doi.org/10.1053/j.otsm. 2007.05.006.

71. Dines JS, Jones K, Maher P, Altchek D. Arthroscopic Management of Full-Thickness Rotator Cuff Tears in Major League Baseball pitchers: the lateralized footprint repair technique. American journal of orthopedics (Belle Mead, NJ). 2016;45(3):128-33. Describes management of full-thickness rotator cuff tears in MLB players using a novel operative technique

72. Reynolds SB, Dugas JR, Cain EL, McMichael CS, Andrews JR. Debridement of small partial-thickness rotator cuff tears in elite overhead throwers. Clin Orthop Relat Res. 2008;466(3):614-21. https://doi.org/10.1007/s11999-007-0107-1.

73. Klouche S, Lefevre N, Herman S, Gerometta A, Bohu Y. Return to sport after rotator cuff tear repair: a systematic review and metaanalysis. Am J Sports Med. 2016;44(7):1877-87. This recent analysis details the overall return-to-play in both professional and competitive athletes. https://doi.org/10.1177/ 0363546515598995.

74. Conway JE. Arthroscopic repair of partial-thickness rotator cuff tears and SLAP lesions in professional baseball players. Orthopedic Clinics. 2001;32(3):443-56.

75. Tibone JE, Elrod B, Jobe FW, Kerlan RK, Carter VS, Shields JC, et al. Surgical treatment of tears of the rotator cuff in athletes. J Bone Joint Surg Am. 1986;68(6):887-91. https://doi.org/10.2106/ 00004623-198668060-00010.

76. Mazoué CG, Andrews JR. Repair of full-thickness rotator cuff tears in professional baseball players. Am J Sports Med. 2006;34(2): 182-9. https://doi.org/10.1177/0363546505279916.

77. Young SW, Safran MR, Dakic J, Nguyen ML, Stroia K. Arthroscopic shoulder surgery in female professional tennis players: ability and timing to return to play. Orthopaedic journal of sports medicine. 2013;1(4_suppl):2325967113S00097.

78. Foulk DA, Darmelio MP, Rettig AC, Misamore G. Full-thickness rotator-cuff tears in professional football players. American journal of orthopedics (Belle Mead, NJ). 2002;31(11):622-4.

79. Tambe A, Badge R, Funk L. Arthroscopic rotator cuff repair in elite rugby players. International journal of shoulder surgery. 2009;3(1): 8-12. https://doi.org/10.4103/0973-6042.50876.

80. Dugas JR, Mathis TP. Partial rotator cuff tears in throwing athletes. Operative Techniques in Sports Medicine. 2016;24(3):196-202. https://doi.org/10.1053/j.otsm.2016.04.007. 